\title{
Rupturas epistemológicas e o discurso sobre Deus. Uma leitura a partir de Michel Foucault Epistemological ruptures and discourse about God. A reading from Michel Foucault
}

\author{
Flávio Augusto Senra Ribeiro* \\ Helder de Souza Silva Pinto**
}

\begin{abstract}
Resumo
$\mathrm{O}$ artigo apresenta o resultado da pesquisa que abordou a investigação sobre as rupturas epistemológicas e o discurso sobre Deus na obra As palavras e as coisas, de Michel Foucault. Intitulada como "Deus, as palavras e as coisas", a pesquisa parcialmente apresentada aqui pretende ser uma colaboração para a análise do que se tem identificado como fenômeno do neo-ateísmo, um tema de grande relevância para a Filosofia da Religião nos dias atuais. Para compreendê-lo, apresentam-se, seguindo a perspectiva foucaultiana, os distintos matizes epistemológicos que sustentam a concepção sobre Deus. Em seus três momentos, o texto apresenta a episteme renascentista e o discurso de Deus, a episteme clássica e a idéia sobre Deus e, por fim, a episteme moderna, a morte de Deus e a morte do homem. Acredita-se que aquilo que se decide na contemporaneidade não seja necessariamente o acabamento do tempo da morte de Deus e a consequente morte do homem, fruto do modo moderno de compreender e tematizar o divino, o infinito, o absoluto ou o verdadeiro, mas uma clara disputa entre variadas perspectivas epistemológicas em suas concretizações científica, política, cultural e religiosa.
\end{abstract}

Palavras-chaves: Michel Foucault, Filosofia da Religião, Epistemologia, Deus, Ateísmo.

\begin{abstract}
The article presents the results of research that investigate on epistemological ruptures and speaking about God in The Order of Things writhed by Michel Foucault. Entitled as "God, words and things," this research partially presented here is intended as collaboration for the analysis of what has been identified as phenomenon of neo-atheism, a topic very important for the Philosophy of Religion today. To understand it, we present, following the Foucaultian perspective, the different epistemological nuances underpinning conception of God. In her three moments, the text presents the Renaissance episteme and the God's discourse, the classical episteme and the idea of God and, finally, the modern episteme, the death of God and man's death. It is believed that what is decided in the contemporary is not necessarily the finish time of the death of God and the consequent man's death, the fruit of modern way of understanding and themes on the divine, the infinite, the absolute or true, but a clear dispute between different epistemological perspectives in their political, cultural and religious diversity achievements.

Keywords: Michel Foucault, Philosophy of Religion, Epistemology, God, Atheism.
\end{abstract}

Artigo recebido em 18 de setembro de 2010 e aprovado em 26 de outubro de 2010.

* Doutor em filosofia pela Universidad Complutense de Madrid. Mestre em Ciência da Religião pela Universidade Federal de Juiz de Fora - UFJF. Professor adjunto da Pontifícia Universidade Católica de Minas Gerais - PUCMG. País de origem: Brasil. E-mail: flaviosenra@ pucminas.br

${ }^{* *}$ Mestre em Filosofia pela Faculdade Jesuíta de Filosofia e Teologia - FAJE. Especialista em Filosofia pela Universidade Federal de Minas Gerais - UFMG. País de origem: Brasil. E-mail:helder.filosofia@ hotmail.com 


\title{
Introdução
}

\begin{abstract}
A todos os que pretendem ainda falar do homem, de seu reino ou de sua liberação, a todos os que formulam ainda questões sobre o que é o homem em sua essência, a todos os que pretendem partir dele para ter acesso à verdade, a todos os que, em contrapartida, reconduzem o conhecimento às verdades do próprio homem, a todos os que não querem formalizar sem antropologizar, que não querem mitologizar sem desmistificar, que não querem pensar sem imediatamente pensar que é o homem quem pensa, a todas essas formas de reflexão canhestras e distorcidas, só se pode opor um riso filosófico - isto é, de certo modo, silencioso. (FOUCAULT, 1990, p.359).
\end{abstract}

Qual pode ser a contribuição de Michel Foucault para a compreensão atual do fenômeno do neo-ateísmo? Com esta pergunta abre-se a oportunidade para uma aplicação da recente pesquisa sobre as rupturas epistemológicas e o discurso sobre Deus na obra As palavras e as coisas de Michel Foucault. ${ }^{1}$ Trata-se de analisar as epistemes descritas por Foucault em As palavras e as coisas e investigar a possibilidade do discurso sobre Deus em cada episteme. Na episteme anterior à idade clássica, o autor reconheceu o lugar do discurso de Deus que fala através do mundo. Na Idade Clássica, alguns discursos sobre Deus são articulados para representá-lo dentro da ordenação do mundo como garantia da verdade. Na episteme moderna surge, pela primeira vez na história, o homem ocupando o lugar do absoluto. Compreendendo os fenômenos de uma episteme é possível articular as imagens e os discursos sobre Deus que nela se formam.

O que se pretende neste artigo é apresentar uma contribuição à compreensão do fenômeno que hoje se tem denominado neo-ateísmo. Curiosamente, a despeito das especificidades em que se constituiu o pensamento moderno e contemporâneo em seu decidido esquecimento de Deus entendido como formulação do princípio regulador da vida, da moral ou da política, observa-se em toda parte a sua permanência, para muito além do que poderia ser uma mera sombra. A emergência no cenário recente de discursos de natureza fundamentalista em certos segmentos religiosos parece ter reacendido uma cruzada científico-filosófica de não muitos, mas ruidosos, combatentes. Alimentados por uma elevada vontade de crer cujo objeto é a não-crença, alguns dos combatentes da cruzada ateísta atacam o domínio religioso que ainda resta nas sociedades moderno-cristãs européias. Não tão enfraquecido quanto possa parecer, a pseudo secularização do Estado

\footnotetext{
${ }^{1}$ Apoio: CNPq. Edital 03/2008. Projeto Niilismo e Religião.
} 
cristão, ali onde o domínio religioso grassa travestido de ações políticas e de controle da pesquisa científica, parece também ser um alvo dos cavalheiros defensores da nova época de luzes que se almeja conquistar. Mas ainda e, muito fortemente, se pode identificar como um preferencial alvo de combate aquele domínio religioso exercido nas sociedades teocráticas onde parece acontecer o mais importante processo de ressignificação cultural, política e religiosa, do leste ao oeste, do sul ao norte do globo. Do domínio cristão europeu e norte-americano ao processo de islamização, em ambos os casos com alguns elementos de radicalismo e belicosidade, em certos casos levados às vias de fato do terrorismo, o neoateísmo dos dias em que vivemos tem levantado, segundo seus críticos, bandeiras pretensamente iluministas, nas quais se inscrevem os lemas do cientificismo, do laicismo e do secularismo. Para os neo-ateus, que nem são maus, nem imorais, sua batalha pela cientificidade, laicidade e caráter secular da ética e da política, o inimigo a ser combatido é aquele da superstição paralisante e o do domínio religioso que escraviza pelo dogmatismo, pelo transcendentalismo e pela negação das condições humanas e sociais para a construção do mundo ético e justo no aquém do transcendental e extra-mundano mundo divino. Em última instância, trata-se de uma elevação do homem e seus feitos. $\mathrm{O}$ ateísmo do passado recente, como este seu filho mais novo, é humanista e, porque não dizê-lo, antropocêntrico. Não se deve deixar de identificar aqui, como parte desse fenômeno, os silenciosos místicos de uma espiritualidade sem Deus, bem como os religiosos que procuram evidenciar uma experiência leiga, livre de crenças institucionalizadas, portanto, crenças sem religiões e também sem Deus. Não menos sem expressão, o neo-ateísmo poderia revelar-se ainda nas múltiplas formas do que também poderia se chamar neo-paganismo. Neste, as formas latentes de uma espiritualidade feminina, difusa, ecológica e mágica também ocupa importante penetração no imaginário religioso. Salvo no horizonte ecologista, talvez, o homem não parece questionado nem em sua pretensão de crer em algo como não sendo Deus ou em si mesmo como fonte de verdade.

Retomando a pergunta que abre este artigo, o que se objetiva aqui é uma leitura que, na ótica estabelecida por Foucault em As palavras e as coisas, favoreça a compreensão desse fenômeno sem ao menos mencioná-lo. Nossa perspectiva é realçar, pela investigação sobre as rupturas epistemológicas estudadas pelo pensador francês, as possibilidades e as impossibilidades de um discurso sobre Deus ali onde ela aparece e onde tampouco se 
apresenta. Passando pelo reconhecimento das condições para a formação das epistemes, é possível aceitar como legítima a ordem do saber que possibilitou reconhecer o lugar ocupado por Deus. Na episteme distinguem-se práticas e discursos que são historicamente possíveis e partilhados por todos que são seus contemporâneos. O discurso sobre Deus se encontra ao lado de outros discursos e participa do mesmo contexto, adaptando-se aos mesmos padrões da cultura onde está inserido. As investigações das condições do saber autorizam uma compreensão de que todos os enunciados são contemporâneos e se expressam por diferentes linguagens. Uma vez aceita essa constatação, não há como sustentar que exista um discurso à frente ou a reboque de seu tempo. Cada formação discursiva revela as condições do saber em diferentes épocas. O saber e as imagens de Deus ou sua ausência se formam com um discurso historicamente situado. Investigar as possibilidades do discurso sobre Deus a partir de As palavras e as coisas, obriga-nos, portanto, a tratar o tema em três diferentes momentos. A episteme anterior à Idade Clássica, a episteme da Idade Clássica e a episteme da Modernidade.

Na perspectiva do autor, na episteme renascentista ${ }^{2}$ Deus fala através das coisas, pois existem condições para essa transparência do discurso de Deus. Para entender esse discurso é necessário saber lê-lo nas coisas do mundo através das quais ele se manifesta nos jogos e nas variações das "semelhanças". Na Idade Clássica, reconhece-se possível, pela razão, explicar a ideia de Deus. O conceito sobre Deus passa a ocupar um lugar na nova ordem fundada nas leis da matemática e distante da magia e da adivinhação. Por fim, se torna clara a mudança ocorrida na episteme moderna a partir do discurso sobre a morte de Deus. Essa afirmação abala o saber, tanto pela experiência da negação quanto pelo silêncio conferido ao tema.

Foucault pode ser considerado um dos filósofos ateus do fim da Modernidade. Em Nietzsche, Foucault busca a base para sustentar a afirmação da morte de Deus como expressão das necessidades demasiadamente humanas. Nessa relação o tema Deus é tocado pelo silêncio intencional, uma vez que Foucault, situando de forma coerente seu pensamento após o de Nietzsche, não pode falar diretamente de Deus como se ele existisse,

\footnotetext{
${ }^{2}$ Não encontramos em As palavras e as coisas a expressão episteme renascentista. A utilização dessa referência ocorre para significar a forma e a condição de possibilidade do conhecimento na época do Renascimento. Foucault não se detém na episteme renascentista, mas usa diferentes formas de referência ao Renascimento para dizer de uma episteme anterior à Idade Clássica.
} 
bem como se ele não existisse, restando-lhe o silêncio. Ao mesmo tempo ele está inserido em um contexto social que utiliza a expressão "Deus" para significar o absoluto ou para dizer das relações com o absoluto.

\section{A Espisteme renascentista e o discurso de Deus}

A força e a presença do discurso sobre Deus devem ser reconhecidas na episteme do século XVI. Retomando a herança da filosofia grega e do pensamento medieval cristão, o sistema de pensamento renascentista foi capaz de abrigar as diferentes concepções da teologia e a visão do cosmos. Defendendo a importância de Foucault para o estudo da teologia, Carrette e Bernauer (2004, p. 2) concordam que "o discurso teológico emerge em cada período da história de acordo com as estruturas epistêmicas que tornam possíveis essas afirmações".

$\mathrm{Na}$ episteme renascentista, diferentes imagens de Deus aparecem descritas nos discursos. Por um lado, tem-se um Deus como figura de razão. Por outro lado, tem-se um Deus próximo da narração naturalista. Como afirmado, as imagens de Deus e o discurso teológico emergem seguindo as condições e estruturas do processo histórico ${ }^{3}$. Considera-se legítima a existência de espaços para o discurso "de" Deus, bem como para o discurso "sobre" Deus na experiência e no saber até a Idade Clássica. ${ }^{4}$

Para Foucault, a episteme anterior à Idade Clássica assume que Deus já teria colocado no mundo suas marcas e a tarefa humana seria a de lê-las e reconhecê-las. A classificação e a leitura dos sinais de Deus presentes na natureza aconteciam, sobretudo, pelo uso das similitudes que possibilitavam reunir, em um corpo de interpretação coerente e sob uma mesma classificação de sentido, muitas coisas diferentes. A percepção de que Deus imprimiu suas marcas em nossa realidade era compatível com a forma de pensar que conferia a ele um espaço de manifestação no mundo finito.

Foucault (1990) procura confirmar a importância das semelhanças como forma de articular e produzir conhecimento. As semelhanças indicam que é possível reconhecer o

\footnotetext{
${ }^{3}$ Sabemos que também a teologia, as imagens de Deus e as diferentes visões religiosas faziam parte da variedade de discursos na cultura da Renascença.

${ }^{4} \mathrm{O}$ discurso que é elaborado sobre Deus pretende dizer algo sobre ele. Esse discurso tende a silenciar o discurso direto de Deus. Para Muchail (2004), o risco que se apresenta é não deixar emergir o discurso original e produzir uma interpretação, tentando a descrição do objeto com um discurso segundo.
} 
que vem de Deus por meio das coisas do mundo que articulam o saber da semelhança. Indica o autor que o sistema das assinaturas ou assinalações estabelece uma relação entre o visível e o invisível, explicando que, se Deus escreveu, ele mesmo deixou sua marca no mundo. A leitura dessas marcas tem como principal trabalho o reconhecimento da existência de Deus. Embora pareça paradoxal afirmar a possibilidade de acesso ao que está fora dos limites do mundo, neste caso, a ideia de que existe uma luz divina que guia os escritos e a manifestação das coisas no mundo nos conduz à realidade que está fora ou é anterior a esse mundo. O conhecimento firma uma relação com Deus através e na medida em que consegue recolher e interpretar seus sinais.

A tarefa do conhecimento pela magia e pela adivinhação objetivava recolher o que foi colocado no mundo por Deus. Segundo Foucault (1990, p. 51), "no esoterismo, as propriedades das palavras, das sílabas e das letras são descobertas por um outro discurso que permanece secreto". O discurso esotérico, fundado em uma ordem que estava além da natureza, era, no entanto, visível na natureza e acessível a um círculo fechado de iniciados. A ordem sob a qual a Idade Média pensa Deus até o Renascimento se baseia na crença de que a capacidade de ordenação humana existe e se expressa como dádiva de Deus. É uma condição do ser humano organizar seu conhecimento para compreender Deus através de sua criação. Deus, como um espírito que não nos engana e com sua sabedoria, havia criado todas as coisas. Nesse ato de criação ele imprimiu sua marca no mundo para que pudéssemos ler sua escrita. A tarefa de quem construiu o saber nessa episteme era a de capacitar-se para ler e compreender as marcas de Deus no mundo. Embora Deus mesmo não esteja presente em nosso mundo, ele se manifesta através das coisas criadas. Só temos o mundo, esse mundo, que se apresenta como nosso limite mas, também, como possibilidade para compreendermos as assinaturas que Deus nele depositou.

\section{A ideia de Deus como representação}

Sob influência do pensamento escolástico, o lugar ocupado pela afirmação da existência de Deus até a Idade Clássica ${ }^{5}$ não poderia ser diretamente questionado. O saber,

\footnotetext{
${ }^{5}$ Foucault indica a passagem do saber nos séculos XVII e XVIII como a primeira de duas importantes descontinuidades na episteme ocidental mais recente. Essa passagem está situada na virada que aconteceu no
} 
na passagem para a época clássica, não se ocupou em confrontar diretamente as questões de fé, mas, ao contrário, dirigiu seu foco para a ordenação das coisas. Essa atitude de reconhecer que o problema dos transcendentais objetivos existe, e de colocá-los em suspensão, desloca o criador do centro do saber. Essa atitude de separação e delimitação dos campos do saber pode ser vista como um primeiro passo para o esquecimento de Deus. A episteme clássica procurou enquadrar os conhecimentos para ordená-los de forma lógica e simples. O saber sobre Deus, em Descartes, aparecerá, segundo Foucault, como garantia de que podemos empreender essa organização e de que ela se moverá em direção à verdade e não ao erro. O Deus cartesiano é um Deus de razão que garante o correto juízo. Partindo da análise do texto de Descartes, Foucault apresenta a episteme da representação como um chão propício para a mudança das ciências empíricas e para o nascimento das ciências humanas. Nessa episteme da representação, a ruptura com o saber construído até o Renascimento abre a possibilidade para a retirada dos transcendentais objetivos do mundo e das coisas.

Razão e racionalidade humana aparecem e são reconhecidas como o único meio de explicar as coisas do mundo. Essa condição para o questionamento das certezas anteriores e para a construção de uma ordem exigida pelo rigor do método científico foi imposta pelo próprio movimento racionalista. Para Ternes (1998, p. 84), "a ciência clássica se constituiu no vazio deixado pela destruição da concepção aristotélica de universo". Porém, para Ternes, "trata-se, sem dúvida, de uma condição necessária, embora não suficiente, para a elaboração da episteme clássica". Segundo este professor da PUC Goiás, a pergunta suscitada pela filosofia apresenta uma dificuldade a ser enfrentada, sendo esta causada pela distância entre a concepção do vazio, que pode indicar um infinito, e o conceito de ilimitado, impossível de ser descrito pela razão.

Como recolocar Deus no mundo uma vez que seu discurso cessou nas coisas de sua criação? Estava colocado para a reflexão teológica o problema de conceituar racionalmente Deus e demarcar os espaços de sua manifestação. Foucault, citando Descartes ${ }^{6}$, afirma: “O mundo ocidental se debateu para saber se a vida era apenas movimento ou se a natureza era bastante ordenada para provar Deus" (FOUCAULT, 1990, p. 90). Mesmo que, de forma

modo de configurar o saber entre a época do Renascimento e a Idade Clássica (século XVI) e a mudança entre a Idade Clássica e a Moderna (Século XIX). (Cf. FOUCAULT, 1990, p.12).

${ }^{6} \mathrm{O}$ texto de Descartes usado por Foucault para esse comentário foi: Regras para a orientação do espírito.

Horizonte, Belo Horizonte, v. 8, n. 18, p.27-64, jul./set. 2010 - ISSN: 2175-5841 
indireta, a "ordem" pudesse ser a garantia da existência do "grande relojoeiro", Deus não poderia ser objeto de provas e análises das ciências. Continua, portanto, a presença de um espaço vazio que tenta ser representado pelos signos do discurso da razão.

Na episteme clássica, a relação entre o signo e a forma de conhecer e decifrar o que ele comunica passa a ter necessidade de uma interpretação para revelar o que comunica o signo ${ }^{7}$. Essa falta de transparência do signo em relação ao que ele revela muda a maneira de expressar o conhecimento. O que não pode ser representado é colocado em suspeita e visto como improvável. Os signos já não trazem diretamente as marcas de Deus. Para serem reveladas, essas marcas necessitam ser significadas e interpretadas. Só há signo enquanto ele pode ser representado, substituído nas relações do conhecimento do que significam. $\mathrm{O}$ signo representado necessita dessa intervenção do conhecimento, não só para ser comunicado, mas para existir. Não é possível afirmar que Deus perde definitivamente seu lugar com a forma clássica de conhecimento. Mas, se ele possui ainda algum lugar, só é possível reconhecê-lo pela mediação da razão ${ }^{8}$. Uma vez estabelecido o princípio de que foi Deus quem criou a capacidade humana de conhecimento racional, é por meio dessa razão organizada e dessa capacidade que se compreendem as impressões deixadas por ele no mundo. Para Foucault, o problema do infinito surge a partir do momento em que as mudanças dos signos saem do espaço soberano para se alojarem ao lado do homem. Gilles Deleuze, recorda o professor Ternes (1998), aponta para a questão que de alguma forma foi esquecida por Foucault. Segundo Deleuze (2005), a maneira de pensar o infinito é uma característica da Idade Clássica na medida em que ela busca dizer o que é o infinitamente perfeito. O desafio para o pensamento surge na medida em que existe necessidade de atribuir uma ordem ao infinito. A extensão de perfeição, caso possa ser elevada ao infinito, só pode ser atribuída a Deus, indica Deleuze (2005). Ao relacionar a quantidade de vezes em que a palavra "infinito” aparece em As palavras e as coisas, José Ternes (1998) comenta que o modo como Foucault utiliza esse conceito não dá margens para reconhecermos alguma forma de transcendente. Segundo Ternes (1998, p. 84), a questão do infinito "não está inteiramente ausente do horizonte do discurso de Les mots e les choses.

\footnotetext{
${ }^{7} \mathrm{O}$ tema dos signos e da sua interpretação foi abordado na palestra sobre Marx, Nietzsche e Freud, realizada em 1967. Na ocasião, Foucault (2005) retoma a ideia de que no século XVI os signos estavam em um espaço homogêneo e que os signos da terra remetiam ao céu.

${ }^{8}$ Junto com a mudança no pensamento humano após Descartes, a teologia também assume nova função ao tentar representar Deus.
} 
Acompanha-o como sua sombra. Como margem obscura que, se retirada, faria, talvez, ruir tudo o que está explícito". Para Ternes, a afirmação mais correta a ser feita é que o problema do infinito estava presente na episteme do século XVII e XVIII mesmo que os pensadores divergissem sobre o modo de pensá-lo.

O Deus de razão não se reconhece mais no universo construído pelo conhecimento do século XVII, o mundo não seguia mais as leis da perfeição esférica e seria necessário redefinir o conceito de perfeição para que ele continuasse a ser atribuído a Deus. "Quando os conteúdos empíricos foram desligados da representação e envolveram em si mesmos o princípio de sua existência, então a metafísica do infinito tornou-se inútil; a finitude não cessou mais de remeter a ela própria." (FOUCAULT, 1990, p. 333). Assim é possível reconhecer que Deus ocupava um lugar na episteme medieval e renascentista e que esse lugar foi questionado pelo saber na busca de conhecer o mundo físico com leis matemáticas, independentes da relação com a magia e as ideias falsas. $\mathrm{O}$ discurso de Deus nas coisas e a possibilidade de acesso a ele, através das coisas do mundo, são substituídos pela ideia e pela representação.

Se o conhecimento em uma episteme é partilhado por todas as formas de saber que dividem o mesmo período, também a teologia deve procurar, nessa nova ordem clássica, um lugar para responder à pergunta acerca da existência ontológica de Deus. Ele deixa de habitar o mundo das coisas e passa a habitar o mundo de conceitos puros e é representado como um grande ordenador cuja ação é percebida no mundo. Em uma existência, não mais por realidade, mas por necessidade, torna-se indispensável que Deus exista para que o mundo seja perfeito e para que o cogito não se engane indefinidamente.

\section{A espisteme moderna, a morte de Deus e a morte do homem}

O discurso sobre Deus e o homem como absoluto encontra um espaço vazio na episteme moderna ${ }^{9}$. O pensamento de Foucault, a partir de Nietzsche, afirma que a morte de Deus supõe o desaparecimento do homem como centro da história moderna. A morte de

\footnotetext{
${ }^{9}$ Para Foucault a episteme moderna se inicia após o pensamento de Kant.
} 
Deus abre espaço para uma liberdade da razão, mas para isso deve ser vencida também a vontade de se estabelecer uma verdade absoluta ${ }^{10}$.

Numa entrevista concedida a M. G. Foy, ao falar sobre o que é um filósofo, Foucault (2005) comenta o momento histórico em que, com Hegel, a filosofia passou a ocupar uma cátedra nas instituições acadêmicas. Esse período coincide com o aparecimento da afirmação da morte de Deus, mas a noção da morte de Deus aparece respondendo a diferentes perguntas do pensamento filosófico.

\begin{abstract}
A noção da morte de Deus não tem o mesmo sentido segundo você a encontre em Hegel, Feuerbach ou Nietzsche. Para Hegel, a Razão assume o lugar de Deus, é o espírito humano que se realiza pouco a pouco. Para Feuerbach, Deus era a ilusão que alienava o Homem; uma vez varrida essa ilusão, é o Homem que toma consciência de sua liberdade. Para Nietzsche, finalmente, a morte de Deus significa o fim da metafísica, mas o lugar permanece vazio; não é absolutamente o Homem que toma o lugar de Deus. (FOUCAULT, 2005, p. 34-35)
\end{abstract}

Junto com o espaço do absoluto é colocado em dúvida o ideal de verdade, ainda que esse ideal se manifeste em forma de ciência. Qualquer verdade absoluta deve ser questionada e a possibilidade de vê-la como erro ou mentira surge no horizonte da liberdade do conhecimento. Para Foucault (1990), foi Nietzsche quem queimou para nós, e antes mesmo que tivéssemos nascido, as promessas mescladas da dialética e da antropologia. Com Nietzsche, o tema da morte de Deus aparece pela primeira vez junto com a retomada da finitude humana.

Porém, segundo Foucault, Kant colocou o sujeito diante das condições de seu conhecimento finito, na analítica da finitude e nas condições transcendentais, o conhecimento não mais pôde ser identificado com a representação clássica. Como recordanos Machado, “diferente de quando conhecer era representar, já não se pode conhecer tudo: Deus, a alma, a totalidade do mundo. O conhecimento é limitado. Os limites do conhecimento humano - porque o homem só pode conhecer o que é sensível - fundam agora a possibilidade do saber." (MACHADO, 2005, p.94).

\footnotetext{
${ }^{10}$ É possível, brevemente, destacar alguns lugares que mostram a presença do tema da morte de Deus ligado à morte do homem em alguns comentadores de Foucault. Ternes (1998) o coloca na reflexão sobre a finitude e a história. Machado (2005) relaciona a morte de Deus com o tema da transgressão e com o ser da linguagem. Deleuze (2005) fala da morte de Deus diante da formação do futuro. Eribon (1990) fala da morte do homem e da morte de Deus quando apresenta os escritos de As palavras e as coisas. Bach (2006) relaciona a morte de Deus com as citações que Foucault faz de Nietzsche. Carrette e Bernauer (2004) reservam ao problema da morte de Deus os lugares onde ela aparece ligada ao saber da teologia negativa e às formas de relação entre a política e a teologia.
} 
Na representação ainda era possível tentar um discurso sobre todas as coisas, o que não é mais possível nos limites do conhecimento. Os limites do conhecimento humano, afirmados na ausência de Deus e em seu caráter de síntese, voltam-se para o mundo sensível e ali fundam a possibilidade das ciências empíricas. Para Foucault, (1990, p. 333), na medida em que as ciências empíricas operam como analíticas da finitude, elas "manifestam o fim da metafísica: a filosofia da vida denuncia a metafísica como véu da ilusão, a do trabalho a denuncia como pensamento alienado e ideologia, a da linguagem, como episódio cultural". A possibilidade de uma reflexão metafísica será retirada do pensamento moderno.

Segundo Foucault, seguindo o método da arqueologia, quando o pensamento se volta para o mundo finito, surge então o que ele chama de dobra. Deleuze considera a dobra "uma relação de forças, em que as forças regionais enfrentam ora forças de elevação ao infinito (desdobramento), de maneira a constituir uma forma-Deus, ora forças de finitude (dobra), de maneira a constituir uma forma-Homem.” (DELEUZE, 2005, p.138). A relação entre as forças constitui tanto a forma-Deus quanto a forma-homem, dependendo de como combinamos as forças que existem na natureza.

Os espaços dessacralizados constituem uma realidade no discurso e no saber modernos. Ainda permanece o fenômeno da divinização de signos e de discursos. A ausência de um absoluto no qual se apoia a verdade deveria ser uma constatação. Porém, mesmo que na episteme moderna o discurso sobre Deus permaneça, não se trata mais de voltar a uma sacralização das práticas humanas. Diante do vazio e do tema da morte de Deus apresentado por Nietzsche, Foucault não coloca mais uma pergunta a ser respondida sobre o lugar em que está Deus, tal como se encontra no parágrafo 125 de A Gaia Ciência. Ele já parte da constatação de que Deus está morto e o que ainda podemos percorrer é o caminho das consequências dessa ausência do limite imposto pela linguagem e do discurso sobre o divino.

Ao falar sobre o humanismo, em entrevista concedida a C. Bonnefoy, em junho de 1966, Foucault (2009) lembra que a cultura atual olha para a história com uma tentação retrospectiva de encontrar o homem em diferentes épocas, inclusive em lugares onde ele não existe ${ }^{11}$. Isso se aprende no ensino comum da cultura moderna, como verdade que serve

\footnotetext{
${ }^{11}$ Foucault afirma que nossa aprendizagem foi feita em cima de uma ilusão criada ao olharmos os séculos anteriores com a visão humanista que surgiu no século XIX. Quando olhamos o saber ocidental nos séculos XVI, XVII e XVIII, percebemos que o homem não tem lugar na cultura. É possível ver o tema de Deus, do
} 
de critério para classificar as ações humanas. Contudo, segundo Foucault (2009), esse desejo de conferir um lugar de rei ao homem não passa de uma ilusão humanista. $\mathrm{O}$ homem como um tema positivo que ocupa o centro da atenção das ciências e da filosofia é relativamente recente. Segundo Machado (2005), essa inspiração de que o humanismo e o homem são invenções recentes está ligada ao fim dos valores absolutos, numa tentativa moderna de substituí-los por outros também finitos.

Acredito que a hipótese de Foucault de que o homem é uma invenção recente é fundamentalmente inspirada na constatação nietzschiana de que "Deus morreu", isto é, de que a modernidade significa o desaparecimento dos valores absolutos, das essências, do fundamento divino e o aparecimento de valores humanos demasiado humanos. Substituição da autoridade de Deus e da Igreja pela autoridade do homem considerado como consciência ou sujeito; substituição do desejo de eternidade pelos projetos de futuro, de progresso histórico; substituição de uma beatitude celeste por um bem-estar terrestre. (MACHADO, 2005, p.85).

Seguindo a sugestão de Nietzsche, ao invés de elevar o homem à condição de absoluto, deve-se reconhecer e aceitar os valores humanos presentes na finitude da vida. Assim, o saber e as ideologias serão capazes de libertar as pessoas do peso moral transcendente que elas carregam, conferindo-lhes a possibilidade de viver a vida como ela se dá. É oportuno considerar que pode acontecer ao homem, como um ser existente e centro das atenções nas ciências, esquecer-se de que houve um tempo em que Deus, o mundo e a ordem ocupavam o lugar do absoluto. "Estamos tão ofuscados pela recente evidência do homem que sequer guardamos na lembrança o tempo em que existia o mundo, sua ordem, os seres humanos, mas não o homem.” (FOUCAULT, 1990, p. 338).

Com a morte de Deus, o homem deixa de existir porque mantinha para com ele um “estranho parentesco". O lugar ocupado por Deus não mais poderá ser ocupado e permanecendo vazio inverte nossa atenção e nossa vontade. Deixamos de olhar para fora e para o infinito para lançarmos um olhar em direção à nossa realidade finita. Esse movimento de desaparecimento não significa que havia um espaço e que agora não há mais, ou que havia um homem no centro e que agora não há mais. $\mathrm{O}$ que ocorre é que o espaço vazio é utilizado para compreender o movimento do saber que migra de uma certeza de algo absoluto, fora do mundo, para uma afirmação da positividade da finitude. $\mathrm{O}$ mas o homem, como centro, está ausente antes da Modernidade. (Cf. FOUCAULT, 2009, p.01). 
conhecimento negativo, descrevendo as coisas pelo que elas não são, é uma face dessa mudança do saber na episteme moderna.

Sobre o homem em Foucault, Candiotto (2007, p. 11) afirma que "sua positividade desprende-se da negatividade, sua normalidade é limitada pela anormalidade, seu papel de sujeito constituinte é o apaziguamento de seu ser constituído, sua consciência reflexiva é precedida de seu ser empírico, sua obra depende da ausência de obra”.

Esse movimento de retomada do lugar finito como algo a ser afirmado e não como ausência de infinito, possibilita uma relação positiva com a realidade humana diante das dificuldades que advêm da aceitação dessa condição. A reviravolta de que fala Foucault se situa por um lado em ter Deus e o infinito como referência para construir o saber sobre o homem e, por outro, na colocação do homem como objeto primeiro da reflexão antropológica. Vê-se oportuno deixar destacados seis aspectos em que aparecem, na obra As palavras e as coisas, as implicações da morte do homem. Em primeiro lugar, Foucault relaciona a morte de Deus com a retomada da finitude antropológica e o super-homem. Em segundo lugar, Foucault destaca que deve ser considerada a possibilidade de o homem não existir. Para o pensador, somente com o fim do homem poderia surgir o super-homem de que fala Nietzsche. Em terceiro lugar, afirma-se que o desaparecimento do homem surge mais como tarefa do que como aceitação. E essa tarefa nos possibilita a liberdade do pensamento, que equivale ao vazio deixado pela ausência de qualquer absoluto. Em quarto lugar, Foucault anuncia a morte de Deus e a morte do Homem em nossos dias, não como ausência de Deus que é afirmado, mas como o fim do homem, ali onde a finitude do Homem tenha se tornado o seu fim. Foucault recorda que é o último homem que anuncia a morte de Deus. No espaço de Deus entra sua linguagem, seu pensamento e o riso transgressor. O homem fica órfão, mas só pode falar, pensar e existir na morte de Deus. Nos dois últimos aspectos que recolocam o desaparecimento do homem, Foucault volta a afirmar sobre o fim do homem. Para o pensador, não mais deveríamos pretender falar do homem e das questões humanas, porque o homem não serve como critério de verdade. Por um lado, o homem também não vale o esforço necessário para tentar reconstruir a verdade nas ciências humanas. Foucault propõe o riso e o silêncio, pois não há o que dizer para além do limite. Por outro, reconhece-se que o homem não é o mais antigo problema que encontramos no saber e nem o mais constante, houve muitos outros antes dele. O homem só 
aparece na Europa após o século XVI, porque mudaram as disposições do saber. Se essas disposições também desaparecerem, o homem desaparecerá assim como apareceu "como um rosto de areia desaparece na praia".

Após a morte do homem como objeto de conhecimento, ressurgem as condições da finitude para organizar o saber no fim da Modernidade. Segundo Deleuze (2005), Feuerbach foi o pensador da morte de Deus e Nietzsche a apresentou de várias formas com a intenção de apontar a morte do homem no para-além-do-homem.

Vencida a tentação da visão retrospectiva da história que busca reconhecer em outras épocas o saber sobre o homem, pode-se afirmar que o homem é uma ilusão recente. $\mathrm{O}$ vazio deixado pela ausência do absoluto conduz o saber para assumir a realidade finita e não mais tentar elevar o homem a uma realidade infinita. Com a constatação da morte de Deus, o saber sobre o homem já não mais se remete para fora, mas se dobra sobre si mesmo na realidade finita. Rompe-se o movimento clássico para o infinito e retoma-se a dobra sobre o finito como espaço a ser afirmado.

\section{Considerações Finais}

Fica evidente o que aqui se pode entrever sobre o fenômeno do neo-ateísmo quando a arqueologia de Foucault foi apresentada neste estudo. Sem mais, o que nos parece é que o fenômeno que hoje se nos apresenta pouco ou quase nada se inscreve em um problema de natureza epistemológica precisa.

Considerado em cada episteme apresentada por Foucault em sua obra As palavras e as coisas, o discurso sobre Deus poderia facilmente detectar-se no neo-ateísmo como fruto de um tempo pós-morte de Deus/morte do homem. No entanto, esta parece ser uma conclusão precipitada. O discurso do neo-ateísmo, embora não explicitado neste artigo em suas características, história e dimensões, pretende ser um discurso verdadeiro. Seu combate pela via da negação do discurso e das instituições religiosas revela-se claramente como possuidor de uma vontade de verdade e de, igualmente, afirmação do homem em seu poder de criação e governança das formas simbólicas, instituições e dos recursos materiais disponíveis. Desconsidera-se por um lado tanto a perspectiva do divino que se manifesta no mundo criado, quanto a ideia de Deus como princípio regulador e assegurador da ordem. 
Mas, por outro lado, ali onde se decide pelo vazio, faz-se uma substituição curiosa, em que a razão, a ciência, a técnica, o Estado se constituem como substituições do conceito negado e da realidade que tal conceito representa. Em última instância, o lugar do homem não se sente abalado sob nenhum sentido ou aspecto.

Uma abordagem crítica do fenômeno do neo-ateísmo nesta perspectiva nos leva necessariamente para o lado daqueles que o tomam com pouca seriedade. O momento atual, considerada a perspectiva nietzschiana aqui reelaborada na perspectiva de Foucault, abandona o tema ao silêncio e ao riso. O grande ateísmo, sinal de inocência e liberdade, não se revela nos ruidosos discursos e combates inflamados, cheios de acusações e ressentimentos. O verdadeiro ateísmo já é hoje apenas indiferença. Se ainda se mantém o tom de combate, pressupõe-se que se reconheça a existência daquilo que se lhe apresenta como opositor. Não parece que o fenômeno neo-ateísta creia estar lutando contra moinhos de vento. Fica confirmada, pela via negativa, que a situação apenas reforça o poder do discurso religioso e a presença, simultânea, dos distintos momentos epistemológicos que, embora apresentados em Foucault entre uma ruptura e outra ao longo da história do Ocidente cristão, acabam por conviver, sob múltiplos aspectos, nos dias atuais.

\section{Referências}

BACH, A. Arqueologia no prefácio de As Palavras e as Coisas. Revista Tempo da Ciência (12) $24: 35-60,2^{\circ}$ semestre 2005.

BACH, A. Michel Foucault e a história arqueológica. 2006. Doutorado em Filosofia. Universidade Federal de São Carlos, São Carlos.

BARBOSA, E. Espaço-tempo e poder-saber. Uma nova episteme? (Foucault e Bachelard). Tempo social. Revista de Sociologia. São Paulo, vol. 7, p.111-120, 1995.

CANDIOTTO, C. Foucault: uma história crítica da verdade. Trans/Form/Ação: Revista de Filosofia, Unesp - Marília, v. 29, n. 02, p. 65-78, 2006.

CANDIOTTO, C. Foucault e a crítica do sujeito e da história. Revista Aulas. Campinas, v. 3, n. 3, p. 1-21, 2007. 
CANDIOTTO, C. Foucault e a verdade. São Paulo, 2005. Tese. (Doutorado em Filosofia)

- Pontifícia Universidade Católica de São Paulo.

CANDIOTTO, C. Michel Foucault e o Problema da Antropologia. Philosophica, Valparaíso, v. 29, n. 1, p. 183-197, 2006.

CARRETTE, J.; BERNAUER, J. (org.). Michel Foucault and theology. Hampshire: Ashgate Publishing, 2004.

DAVIDSON, A. I. (Org.). Foucault and his interlocutors. Chicago: Univ. of Chicago Press, 1997.

DELEUZE, G.. Foucault. São Paulo: Brasiliense, 2005.

ERIBON, D. Michel Foucault. 1926-1984. São Paulo: Companhia das Letras, 1990.

ESTRADA, J. A. Deus nas tradições filosóficas. Aporia e problemas da teologia natural. Vol. I. São Paulo: Paulus, 2003a.

ESTRADA, J. A. Deus nas tradições filosóficas. Da morte de Deus à crise do sujeito. Vol. II. São Paulo: Paulus, 2003b.

ESTRADA, J. A. Imagens de Deus. A filosofia ante a linguagem religiosa. São Paulo: Paulinas, 2007.

FOUCAULT, M. A ordem do discurso. Aula inaugural no Collège de France (1970). 14. ed. São Paulo: Edições Loyola, 2006a.

FOUCAULT, M. Arqueologia do saber. 7. ed. Rio de Janeiro: Forense Universitária, $2007 \mathrm{a}$.

FOUCAULT, M. A hermenêutica do sujeito. Curso dado no Collège de France (19811982). 2.ed. São Paulo: Martins Fontes, 2006e.

FOUCAULT, M. A verdade e as formas jurídicas. 3. ed. 5. reimpressão. Rio de Janeiro: Nau Editora, 2009.

FOUCAULT, M. Arqueologia das ciências e história dos sistemas de pensamento. 2. ed. Rio de Janeiro: Forense Universitária, 2005.

FOUCAULT, M. As palavras e as coisas. Uma arqueologia das ciências humanas. 5. ed. São Paulo: Martins Fontes, 1990.

FOUCAULT, M. Estética. Literatura e pintura, música e cinema. 2. ed. Rio de Janeiro: Forense Universitária, 2006c.

FOUCAULT, M. Ética, sexualidade, política. 2. ed. Rio de Janeiro: Forense Universitária, 2006d. 
FOUCAULT, M. História da Loucura. 8. ed. São Paulo: Perspectiva, 2007b.

FOUCAULT, M. História da sexualidade. O uso dos prazeres. 6. ed. Rio de Janeiro: Graal, 1988.

FOUCAULT, M. História da sexualidade. O cuidado de si. 4. ed. Rio de Janeiro: Graal, $1985 b$.

FOUCAULT, M. História da sexualidade. A vontade de saber. 8. ed. Rio de Janeiro: Graal, 1985a.

FOUCAULT, M. L'homme est-il mort? Entrevista com C. Bonnefoy. Disponível em <http://www.unb.br/fe/tef/filoesco/foucault/hommemort.html> Acesso em: 02 de abril de 2009.

FOUCAULT, M. Microfísica do poder. 11. ed. Rio de Janeiro: Graal, 1993b.

FOUCAULT, M. Problematização do sujeito. Psicologia, psiquiatria e psicanálise. 2. ed. Rio de Janeiro: Forense Universitária, 2006b.

FOUCAULT, M. Vigiar e punir. História da violência nas prisões. 10. ed. Petrópolis: Vozes, 1993a.

KREMER-MARIETTI, A. (Org.). Introdução ao pensamento de Michel Foucault. Rio de Janeiro: Zahar Editores, 1977.

LUCARINY, J. G. D. A morte de Deus e a morte do Homem no pensamento de Nietzsche e de Michel Foucault. Rio de Janeiro, 1998. Dissertação (Mestrado em Filosofia). Universidade Estadual do Rio de Janeiro.

MACHADO, R. Foucault, a ciência e o saber. 3. ed. Rio de Janeiro: Jorge Zahar Editor, 2006.

MACHADO, R. Foucault, a filosofia e a literatura. 3. ed. Rio de Janeiro: Jorge Zahar Editor, 2005.

MARTON, S. Foucault, leitor de Nietzsche. In: RIBEIRO, R. J. (org.). Recordar Foucault. São Paulo: Editora Brasiliense, 1985.

MATOS, H. C. J. Introdução à história da Igreja. Vol. I. 5. Ed. Belo Horizonte: Editora O Lutador, 1997a.

MATOS, H. C. J. Introdução à história da Igreja. Vol. II. 5. Ed. Belo Horizonte: Editora O Lutador, 1997b.

MCCALL, C. Autonomy, religion, \& revolt in Foucault. Journal of Philosophy \& Scripture, Vol. 2, 2004. Disponível em: <http:/ / www.philosophyandscripture.org/ CoreyMcCall.pdf $>$ Acesso em: 11 de abril 2009.

Horizonte, Belo Horizonte, v. 8, n. 18, p.27-64, jul./set. 2010 - ISSN: 2175-5841 
MUCHAIL, S. T. A trajetória de Michel Foucault. Extensão. Cadernos da Pró-reitoria de Extensão da PUC Minas: Belo Horizonte, v.2, n.1, p.7-14, fev. 1992.

MUCHAIL, S. T. Foucault. Simplesmente. São Paulo: Loyola, 2004.

NALLI, M. Foucault e a Fenomenologia. São Paulo: Loyola, 2006.

NIETZSCHE, F. W. A gaia ciência. São Paulo: Companhia das Letras, 2001.

NIETZSCHE, F. W. A genealogia da moral. São Paulo: Companhia das Letras, 2001.

NIETZSCHE, F. W. O anticristo. São Paulo: Companhia das Letras, 2007.

OROPAllO, M. C.. A presença de Nietzsche no discurso de Foucault. São Paulo, 2005. Dissertação. (Mestrado em Filosofia) - Universidade São Judas Tadeu.

PIRES, M. J. Teologia e o poder da palavra: desafio renascentista. In: Revista da

Faculdade de Letras, língua e literatura XIII. Porto, 1996. Disponível em <http:/ /

ler.letras.up.pt/ uploads/ ficheiros/2725.pdf> Acesso em: 20 de fevereiro de 2009.

PORTOCARRERO, V. M. Foucault e a questão da representação. Cadernos de Filosofia Contemporânea, Rio de Janeiro, v. 2, p. 39-51, 1999.

RAJCHMAN, J. Foucault. A liberdade da filosofia. Rio de Janeiro: Zahar, 1987.

TERNES, J. Michel Foucault e a idade do homem. Goiânia: Ed. UCG; Ed. da UFG, 1998.

VALLS, Álvaro Luiz Montenegro. O fato absoluto. In: OLIVEIRA, Manfredo; ALMEIDA, Custódio. O Deus dos Filósofos modernos. Rio de Janeiro: Vozes; Porto Alegre:

Universidade Federal do Rio Grande do Sul, 2002. p.241-246..

VAZ, H. C. L. Escritos de filosofia. Filosofia e Cultura. São Paulo: Edições Loyola, 1997.

VEYNE, Paul. Como se escreve a história. 4. ed. Brasília: UnB, 1998. 